\title{
Morphological changes in the liver and kidneys of rats subjected to terminal ileum exclusion during obstructive cholestasis ${ }^{1}$
}

\author{
Evandro Luis de Oliveira Costa ${ }^{\mathrm{I}}$, Geraldo Magela de Azevedo Jrr ${ }^{\mathrm{II}}$, Andy Petroianu ${ }^{\mathrm{III}}$
}

DOI: http://dx.doi.org/10.1590/S0102-86502014000600001

${ }^{\mathrm{I}} \mathrm{PhD}$, Volunteer, Department of Surgery, Faculty of Medicine, Minas Gerais Federal University (UFMG), Belo Horizonte-MG, Brazil. Acquisition and interpretation of data, statistical analysis, designed the protocol, technical procedures, manuscript writing.

IIPhD, Volunteer, Department of Morphology, Biological Sciences Institute, UFMG, Belo Horizonte-MG, Brazil. Macroscopic and histopathological examinations.

IIIPhD, Full Professor, Department of Surgery, Faculty of Medicine, UFMG, Belo Horizonte-MG, Brazil. Designed the protocol, intellectual and scientific content of the study, provided guidelines for the surgical intervention, supervised all phases of the study.

\section{ABSTRACT}

PURPOSE: To investigate the effects of ileal exclusion on hepatic and renal morphology in extra-hepatic cholestasis.

METHODS: Twenty four rats were distributed into three groups. Group 1 (control) underwent laparotomy and laparorrhaphy. The animals in groups 2 and 3 underwent hepatic duct ligature and kept in cholestasis for four weeks. After this period, the rats in groups 2 and 3 underwent internal biliary derivation. In Group 3, the last ten centimeters of the terminal ileum were by passed and excluded. Four weeks later, histological and biochemical analysis were performed in all animals of the three groups.

RESULTS: In Group 1, no abnormalities regarding hepatic morphology were observed. All animals from groups 2 and 3 presented hepatic fibrosis. No difference was observed between the two groups. No morphological differences in renal histology could be identified among the three groups. There were differences in AST $(\mathrm{p}<0.05)$, ALT $(\mathrm{p}<0.05)$, direct bilirubin $(\mathrm{p}<0.05)$, VGT $(\mathrm{p}<0.05)$, urea $(\mathrm{p}<0.05)$ and creatinine $(\mathrm{p}<0.05)$ in Group 3 compared to control.

CONCLUSION: The distal ileum exclusion had no influence upon the hepatic and renal morphological alterations, and biochemical liver and kidney tests have worsened.

Key words: Liver Cirrhosis. Cholestasis. Ileum. Liver. Kidney. Histology. Rats. 


\section{Introduction}

Cholestatic diseases affect all age groups, have a limited number of treatment options and can develop into hepatic fibrosis and cirrhosis, as well as extra-hepatic manifestations, such as hepatic encephalopathy, intractable pruritus and metabolic bone disease, among others.

Hollands et al. ${ }^{1}$ proposed bypassing the terminal ileum, as a way of improving pruritus in children with progressive intra-hepatic familial cholestasis (PIFC). Besides improving the pruritus, there was an improvement in biochemical liver function tests and in liver histology in most subjects; however, follow-up time was short, and patients were few.

In cholestasis, ileocolic bypass would diminish the bile acid reabsorbed in the terminal ileum, increase its fecal excretion and reduce their building up in the liver. Besides the effects on the liver, diminishing circulating bile acids would reduce burdening the kidney on eliminating these compounds. The aim of this paper is to assess the effects of excluding the terminal ileum (ileocolic bypass) on the morphology of the liver and kidneys of rats with extra-hepatic cholestasis.

\section{Methods}

This study was authorized by the Animal Experimentation Ethics Committee (CETEA - UFMG), protocol number 041/2008.

Twenty four adult Wistar rats were used weighing between $240 \mathrm{~g}$ and $320 \mathrm{~g}$, distributed into three groups of eight animals.

Group 1: Control $(\mathrm{n}=8)$

Group 2: Ligature of the hepatic duct combined with internal biliar drainage $(n=8)$

Group 3: Ligature of the hepatic duct combined with internal biliar drainage and exclusion of the terminal ileum (ileocolic bypass) $(n=8)$.

All the animals were allocated to the same place and had free access to food and water.

The animals were submitted to surgical procedures under aseptic conditions and anesthetized by intramuscular injection with a xylazine $2 \%$ and ketamine $10 \%$ solution in $0.15 \mathrm{mg} / \mathrm{kg}$ and $0.25 \mathrm{mg} / \mathrm{kg}$ doses respectively. During proceedings, breathing and heart rates, respiratory movements and voluntary movements were noted. After the operations were over, the animals were each put in a ventilated place and watched until they had fully recovered from the anesthetic.

The animals in Group 1 underwent laparatomy and laparorrhaphy. The animals in groups 2 and 3 first underwent laparotomy and section of the common bile duct, between ligatures of 4-0 silk sutures. Four weeks later, all the animals in groups 2 and 3 were reoperated on.

Internal bile duct drainage was carried out on the animals in Group 2. This consisted of hepaticduodenostomy with the aid of a $4 \mathrm{Fr}$ nelaton catheter measuring $4 \mathrm{~cm}$. One end of this catheter was connected to the bile duct and the other was introduced into the duodenum.

In addition to bile duct drainage, similar to that performed on the animals in Group 2, the animals in Group 3 had the ten terminal centimeters of the ileum excluded, starting from the ileocecal papillae. The proximal segment of the ileum was connected to the ascending ileum colon (bypass). The distal segment was closed off and excluded (Figure 1).

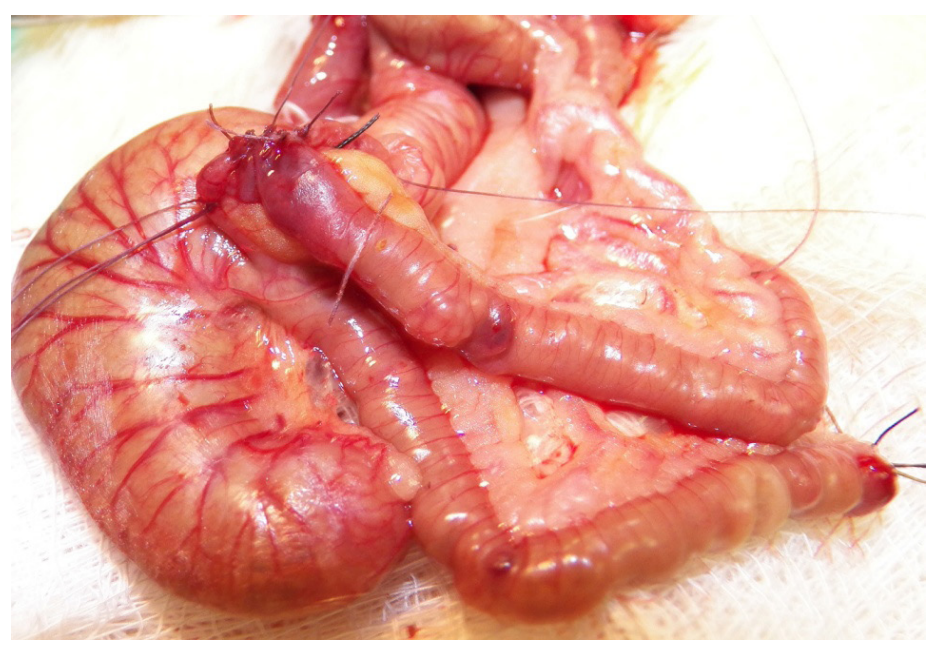

FIGURE 1 - Ileocolic anastomosis (white arrow). Segment of the ligated distal ileum (black arrow).

At the end of eight weeks after the procedures started, all the animals from the three groups were put to death by a lethal injection of ketamine and xylazine. About $5 \mathrm{ml}$ of blood were collected by intra-cardiac puncture and the liver and kidneys removed for histological analysis.

The blood from each animal was put into Eppendorf tubes, kept protected from the light and sent for biochemical testing (AST, ALT, VGT, alkaline phosphatase, bilirubins, creatinine and urea). All the laboratory tests were done using the same apparatus (Cobas Mira Plus $^{\circledR}$ - Roche Diagnostic Systems - Nutley - New Jersey).

Livers and kidneys removed for histological testing were washed with running water and fixed with $10 \%$ formaldehyde solution. They were then embedded in paraffin and hematoxylin and eosin coloring, Gomori trichrome and PAS (periodic acid Schiff). Histological analysis was carried out by a pathologist who did not know which group the organs belonged to (blind study). 
Hepatic fibrosis intensity was analyzed, using the Ishak score ${ }^{2}$, ranging from 0 to 6 , whereby 0 stands for absence of fibrosis and 6 for presence of hepatic cirrhosis, while 1 to 5 show hepatic fibrosis intensities in ascending order. Histological aspects in the kidneys were also seen, when looking for inflammatory processes, glomerular alterations, or other structural changes.

The results obtained were analyzed using version 15.0 of the SPSS (Statistical Package for the Social Sciences) program. The Fisher and Pearson tests were used. The significance level was $\mathrm{p}<0.05$.

\section{Results}

No hepatic cirrhosis or fibrosis was found in the animals in Group 1 (Figure 2). The kidneys were normal with no macroscopic and microscopic alterations.

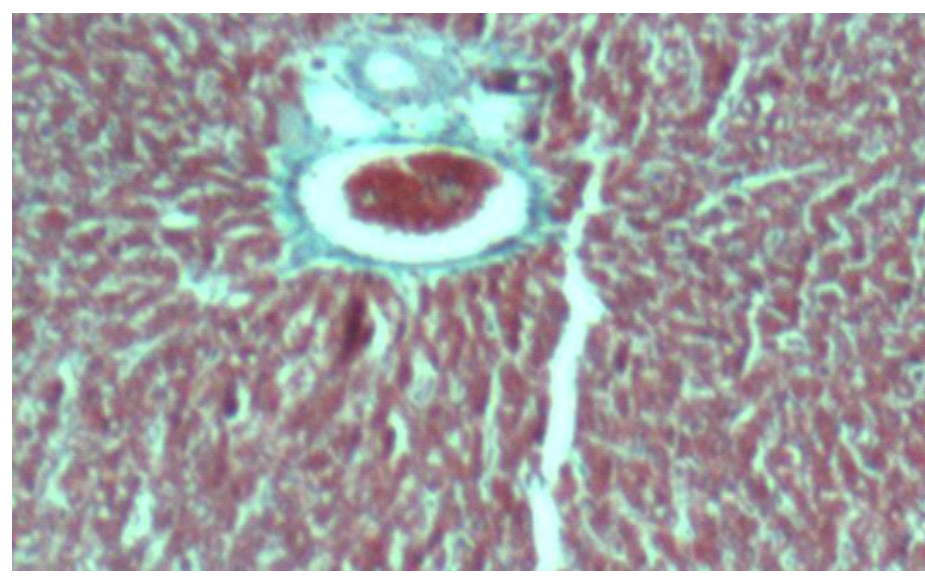

FIGURE 2 - Normal histology of rat from the control Group (Gomori trichrome $-\mathrm{x} 400)$.

The livers of all the rats in groups 2 and 3 had increased in size, had hardened and had a greenish tinge. All the biliodigestive anastomoses were obvious. As to the animals in group 3, no fistulae in the ileocolic anastomoses or dehiscence in the closure of the excluded ileum segments were observed. No ascites was seen in the animals from groups 2 and 3. The macroscopic appearance of the kidneys was preserved.

Microscopic evaluation found hepatic fibrosis established in all the rats from groups 2 and 3, but in different stages (Figure 3). No hepatic cirrhosis was detected. Stage 3 predominated in both groups 2 and 3. There was a difference in hepatic fibrosis intensity on comparing Group 2 and control $(\mathrm{p}=0.003)$ and Group 3 and control $(\mathrm{p}=0.001)$. There was no comparative difference between groups 2 and $3(p>0.05)$ (Table 1).

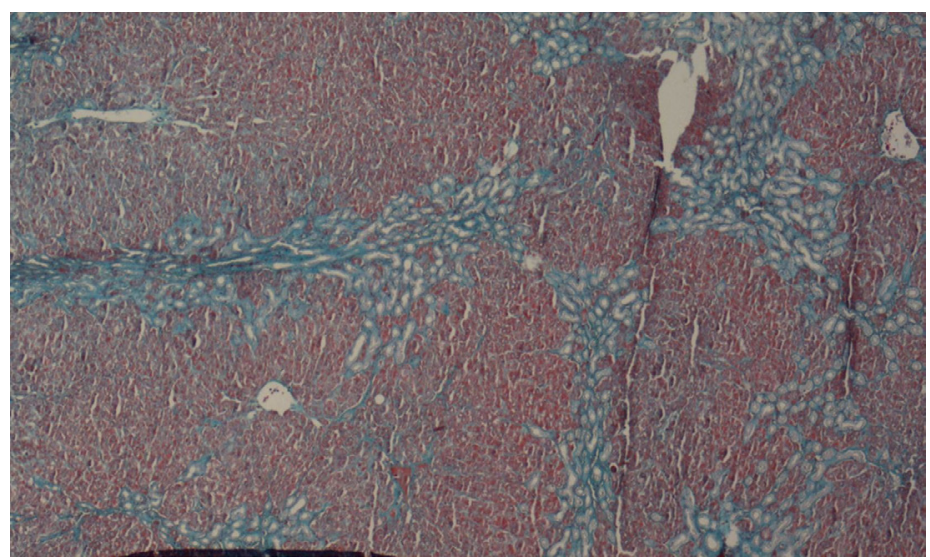

FIGURE 3 - Histological apparence of liver fibroses score 3 (Ishak et $\left.a l .{ }^{2}\right)$ Gomori trichrome $\left.-\mathrm{x} 100\right)$.

TABLE 1 - Intensity of hepatic fibrosis in groups 1, 2, and 3 of the study, according to a scoring system by Ishak et al. ${ }^{2}$.

\begin{tabular}{c|ccc}
\hline Animals & Group 1 & Group 2 & Group 3 \\
\hline 1 & 0 & 5 & 3 \\
2 & 0 & 1 & 3 \\
3 & 0 & 1 & 3 \\
4 & 0 & 3 & 2 \\
5 & 0 & 2 & 1 \\
6 & 0 & 3 & 3 \\
7 & 0 & 3 & 3 \\
8 & 0 & 3 & 3 \\
\hline Pearson Test & Groups 1:2 & Groups 1:3 & Groups 2:3 \\
\hline P value & $0.003 *$ & $0.001 *$ & 0.613 \\
\hline
\end{tabular}

Ishak et al. ${ }^{2}$ scoring system

0- No fibrosis

1 - Fibrous expansion of some portal areas, with or without short septae

2 - Fibrous expansion of most of the portal areas, with or without short septae

3 - Fibrous expansion of most portal areas with occasional portal to portal (PP) brigdes

4 - Fibrous expansion of portal areas, with pronounced PP bridges as well as portal-center (PC) bridges

5 - Pronounced PP and/or bridges with occasional nodules

6 - Cirrhosis.

Group 1: Control; Group 2: Ligature of the hepatic duct combined with internal biliary drainage; Group 3: Ligature of the hepatic duct combined with internal biliary drainage and terminal ileum exclusion.

The kidney structure of all the animals in Group 1 was normal under an optic microscope. No macroscopic or microscopic alterations were identified in the animals in groups 2 and 3, except for a deposit of bile pigments (Figure 4). 


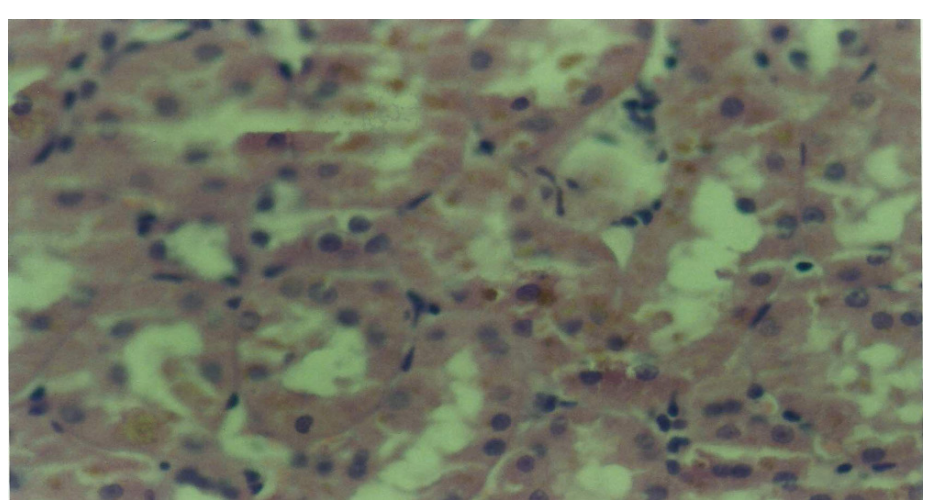

FIGURE 4 - Kidney rat from Group 3 (PAS staining - x400). Bile Pigment: white arrow.

In biochemical liver and kidney tests, no differences between groups 1 and 2 were seen. Comparing Group 3 and control, there was an increase in ALT $(p=0.0480)$, AST $(p=$ $0.037)$, direct bilirubin $(p=0.032), \gamma \mathrm{GT}(\mathrm{p}=0.010)$, creatinine ( $p$ $=0.003)$ and urea $(\mathrm{p}=0.002)($ Table 2$)$.

TABLE 2 - Mean and standard error values of the average of biochemical liver and kidney groups 1,2 and 3 .

\begin{tabular}{l|ccc}
\hline & Group 1 & Group 2 & Group 3 \\
& & & \\
\hline Albumin & $2.26 \pm 0.13$ & $2.20 \pm 0.29$ & $2.12 \pm 0.24$ \\
ALT & $87.70 \pm 6.3$ & $91.14 \pm 24.2$ & $\mathbf{1 2 3 . 6} \pm \mathbf{3 5 . 2} * *$ \\
AST & $213.2 \pm 68.1$ & $210.1 \pm 55.5$ & $\mathbf{3 6 0 . 2} \pm \mathbf{2 2 2 . 1 * *}$ \\
Direct & $0.06 \pm 0.04$ & $0.05 \pm 0.06$ & $\mathbf{0 . 2 6} \pm \mathbf{0 . 2 8} * *$ \\
bilirubin & & & \\
Indirect & $0.05 \pm 0.04$ & $\mathbf{0 . 1 9} \pm \mathbf{0 . 1 1} *$ & $0.29 \pm 0.28$ \\
bilirubin & & & \\
Alkaline & $434.7 \pm 119.1$ & $397.8 \pm 165.8$ & $392.8 \pm 196.1$ \\
Phosphatase & & & \\
yGT & $1.05 \pm 0.62$ & $2.55 \pm 1.66$ & $\mathbf{3 . 9 5} \pm \mathbf{2 . 8 0 * *}$ \\
Creatinine & $0.4 \pm 0.10$ & $0.4 \pm 0.12$ & $\mathbf{0 . 6 5} \pm \mathbf{0 . 1 1} * * *$ \\
Urea & $41.75 \pm 5.85$ & $49.13 \pm 9.7$ & $\mathbf{9 2 . 9 0} \pm \mathbf{5 1 . 2 * * *}$ \\
\hline
\end{tabular}

ALT: alanine aminotransferase; AST: aspartate aminotransferase;

y GT: gamma glutamyl transferase; $p$ : $p$ value; * $p<0.05$

Group 1: Control;

Group 2: Ligature of the hepatic duct associated with internal biliary drainage

Group 3: Ligature of the liver duct associated with internal biliary drainage and exclusion of the terminal ileum

$*$ : $p<0.05$, between group 2 and control

$* *: \mathrm{p}<0.05$, between group 3 and control

***: $\mathrm{p}<0.05$, between group 3 and control and between groups 2 and 3 .

Comparing groups 2 and 3, there was no difference in the hepatic function tests, but the serum creatinine $(p=0.007)$ and urea $(p=0.014)$, concentrations rose (Table 2$)$.

\section{Discussion}

This paper assessed the effects on hepatic and renal morphology in rats with extra-hepatic cholestasis, after internal biliary drainage and terminal ileum exclusion (bypass). According to Hollands et al. ${ }^{1}$, the terminal ileum bypass used to treat pruritus also improved liver architecture and biochemical liver tests in children with progressive familial intrahepatic cholestasis (PFIC). But other studies indicated different results from those of Hollands et al..$^{3-5}$.

In this work, ileal bypass was applied to the murine hepatic fibrosis model created by Kountouras et al. ${ }^{6}$, in order to assess its effect on the morphology of the liver and kidneys, which are organs that in extra-hepatic cholestasis suffer damage mainly because of accumulated acids and other metabolites not properly excreted in the bile.

Records of alterations in the enterohepatic cycle, in patients with ileitis and extensive ileum resections, point to the possibility of using or associating ileum exclusion or terminal ileum bypass in cholestatic disease treatment ${ }^{7}$.

Bile salts are largely reabsorbed in the terminal ileum (enterohepatic cycle); thus excluding the last ten centimeters of the ileum would lessen reabsorption of bile acids by increasing their fecal excretion and lowering the quantity in circulation, as well their buildup in the liver and kidneys. Costa et al. ${ }^{8}$ assessed the morphological effects of resectioning the distal portion of terminal ileum in rats subjected to ligature of the common hepatic duct. They noted that hepatic fibrosis was less intense in animals with a resectioned terminal ileum. Their biggest query was that there was no bilioenteric flow. Some form of regulation and counterregulation involving the terminal ileum and liver in cholestasis may be questioned.

Studies show that there is an improvement in hepatic fibrosis after biliary drainage in rats, even when the hepatic architecture is not normalized. Most of such studies used a two or three week period of hepatic duct ligature prior to biliary drainage ${ }^{9,10}$. There was an improvement in biochemical hepatic function tests in most of them following biliary drainage, except in the studies by Younes et al. ${ }^{11}$ Marinelli Ibarreta et al. ${ }^{12}$, which showed hepatic lesion progression, and biochemical decline, mostly hypoalbuminemia.

It was expected that in the group of animals subjected to the ileocolic bypass, with exclusion of the terminal ileum, morphology and the hepatic biochemical tests would improve; however, the results obtained disclosed persistent hepatic fibrosis and biochemical decline. 
These results, which clash with those of Hollands et al. ${ }^{1}$, may be attributed to the difference between species used in the studies, that is, rats and humans have different responses to distal ileum exclusion. Furthermore, the four week cholestasis period in rats may be linked to important cell damage in the liver cells, culminating in hepatic fibrosis and functional alterations in the liver, not forgetting that four weeks in the life cycle of rats is a long time for them to be exposed to adverse conditions.

In cholestasis, hepatic capacity for metabolizing and excreting toxic substances is lost, causing renal overload ${ }^{13,14}$. The kidneys become the major route for the body to excrete toxic substances, leading to increased exposure to nephrotoxic substances, resulting in disorders such as kidney failure and hepatorenal syndrome ${ }^{13-15}$. Hemodynamic alterations such as peripheral renal vasodilatation, bile acid and bilirubin nephrotoxidity and increased oxidative stress are involved in the physiopathology of this type of kidney failure ${ }^{16-18}$.

No morphological alterations characteristic of this type of kidney failure were described ${ }^{19,20}$. Apparently only functional alterations occur ${ }^{19,20}$. The results of this study corroborate literature, since it shows the worsening of biochemical renal tests in the rats submitted to ileocolic bypass, but did not, however, observe histological lesions in such animals' kidneys.

The results of this work may raise queries regarding the use of ileocolic bypass in other forms of cholestasis, other than as originally prescribed, that is, for pruritus in patients with progressive familial intra-hepatic cholestasis (PFIC), although not yet cirrhotic, despite some studies on humans also querying this indication ${ }^{3-5}$.

\section{Conclusion}

Terminal ileum exclusion associated with biliary drainage did not improve hepatic and renal morphologies in extra-hepatic murine cholestasis, but did worsen biochemical liver and kidney tests.

\section{References}

1. Hollands CM, Rivera-Pedrogo FJ, Gonzalez-Vallina R, Loretde-Mola O, Nahmad M, Burnweit CA. Ileal exclusion for Byler's disease: an alternative surgical approach with promising early results for pruritus. J Pediatr Surg. 1998 Feb;33(2):220-4. PubMed PMID: 9498390.

2. Ishak K, Baptista A, Bianchi L, Callea F, De Groote J, Gudat F, DenK H, Desmet V, Korb G, MacSween RNM, Phillips MJ, Portmann BG, Poulsen H, Scheuer PJ, Schmid M, Thaler H. Histological grading and staging of chronic hepatitis. J Hepatol. 1995 Jun;22(6):696-9. PubMed PMID: 7560864

3. Kalicinski PJ, Ismail H, Jankowska I, Kamiński A, Pawłowska
J, Drewniak T, Markiewicz M, Szymczak M. Surgical treatment of progressive intrahepatic cholestais: comparison of partial external biliary diversion and ileal bypass. Eur J Pediatr Surg. 2003 Oct;13(5):307-11. PubMed PMID: 14618520.

4. Davis AR, Rosenthal P, Newman T. Nontransplant surgical interventions in progressive familial intrahepatic cholestasis. J Pediatr Surg. 2009 Apr;44(4):821-7. doi: 10.1016/j.jpedsurg.2008.07.018.

5. Jacquemin E. Progressive familial intrahepatic cholestasis. Clin Res Hepatol Gastroenterol. 2012 Sep;36 Suppl 1:S26-35. doi: 10.1016/ S2210-7401(12)70018-9.

6. Kountouras J, Billing BH, Scheuer PJ. Prolonged bile duct obstruction: a new experimental model for cirrhosis in the rat. Br J Exp Pathol. 1984 Jun;65(3):305-11. PubMed PMID: 6743531.

7. Hofmann AF. Inappropriate ileal conservation of bile acids in cholestatic liver disease: homeostasis gone awry. Gut. 2003 Sep;52(9):1239-41. PubMed PMID: 12912852.

8. Costa ELO, Azevedo Jr GM, Petroianu A. Influence of terminal ileum resection on hepatic fibrosis provoked by ligature of common bile duct in female rats. Rev Col Bra. Cir. 2006 Jan-Feb;33 (1):1923. doi: 10.1590/S0100-69912006000100006.

9. Zimmermann H, Reichen J, Zimmermann A, Sägesser H, Thenisch B, Höflin F. Reversibility of secondary biliary fibrosis by biliodigestive anastomosis in the rat. Gastroenterology. 1992 Aug;103 (2):579-89. PubMed PMID: 1634077

10. Li W, Chung CS. An improved rat model of obstructive jaundice and its reversal by internal and external drainage. J Surg Res. 2001 Nov;101(1):4-15. PubMed PMID: 11676548.

11. Younes RN, Vydelingum NA, Derooij P, Scognamiglio F, Andrade L, Posner MC, Brennan MF. Metabolic alterations in obstructive jaundice: effect of duration of jaundice and bile-duct decompression. HPB Surg. 1991 Mar;5(1):35-48. doi: 10.1155/1991/27457.

12. Marinelli Ibarreta A, Sánchez Movilla A, Izquierdo F, Burgos Lázaro F, Arce Alvarez A, del Castillo-Olivares Ramos JL. Cambios morfopatológicos pre y postderivación biliodigestiva en cirrosis experimental por ligadura de via biliar em rata. Rev Esp Enferm Dig. 1995 Jan;87(1):25-31. PubMed PMID: 7727164.

13. Israeli BA, Bogin E. Biochemical changes in liver, kidney and blood associated with common bile duct ligation. Clin Chim Acta. 1986 Oct;160(2):211-21. PubMed PMID: 3780011.

14. Fogarty BJ, Parks RW, Rowlands BJ, Diamond T. Renal dysfunction in obstructive jaundice. Br J Surg. 1995 Jul;82(7):877-84. PubMed PMID: 7648096

15. Gentilini P, La Villa G. Liver-kidney pathophysiological interrelationships in liver diseases. Dig Liver Dis. 2008 Dec;40(12):909-19. doi: 10.1016/j.dld.2008.05.013. Epub 2008 Jul 14.

16. Betjes MG, Bajema I. The pathology of jaundice-related renal insufficiency: cholemic nefrosis revisited. J Nephrol. 2006 MarApr;19(2):229-33. PubMed PMID: 16736428.

17. Torres AM. Renal elimination of organic anions in cholestasis. World J Gastroenterol. 2008 Nov;14(43):6616-21. doi: 10.3748/ wjg.14.6616.

18. Fickert P, Krones E, Pollheimer MJ, Thueringer A, Moustafa T, Silbert D, Halilbasic E, Yang M, Jaeschke H, Stokman G, Wells RG, Eller K, Rosenkranz AR, Eggertsen G, Wagner CA, Langner $\mathrm{C}$, Denk H, Trauner M. Bile acids trigger cholemic nephropathy in common bile-duct-ligated mice. Hepatology. 2013 Dec;58(6):205669. doi: 10.1002/hep.26599. Epub 2013 Oct 15.

19. Rodrigo R, Avalos N, Orellana M, Bosco C, Thielemann L. Renal effects of experimental obstructive jaundice; morphological and functional assessment. Arch Med Res. 1999 Jul-Aug;30(4):275-85. PubMed PMID:0573628.

20. Pereira RM, dos Santos RA, Oliveira EA, Leite VH, Dias 
Costa ELO et al.

FL, Rezende AS, Costa LP, Barcelos LS, Teixeira MM, Simoes e Silva AC. Development of hepatorenal syndrome in bile duct ligated rats. World J Gastroenterol. 2008 Jul;14(28):4505-11. doi: 10.3748/ wjg.14.4505.

\section{Correspondence:}

Prof. Andy Petroianu

Avenida Afonso Pena, 1626/1901

30130-005 Belo Horizonte - MG Brasil

Tel.: (55-31)8884-9192

Fax: (55-31)3274-7744

petroian@gmail.com

Received: Jan 16, 2014

Review: March 18, 2014

Accepted: April 22, 2014

Conflict of interest: none

Financial sources: National Council for Scientific and Technological Development (CNPq) and Minas Gerais Research Foundation (FAPEMIG)

${ }^{1}$ Research performed at Laboratory of Experimental Surgery, Department of Surgery, Medicine School, Minas Gerais Federal University (UFMG), Belo Horizonte-MG, Brazil. Part of PhD degree thesis, Postgraduate Program in Sciences Applied to Surgery and Ophthalmology, UFMG. Tutor: Andy Petroianu. 